\title{
ENVOLVIMENTO PESSOAL E INTERAÇÃO EFETIVA EM ENFERMAGEM*
}

\author{
Silvia Cristina Neves** \\ Edelia del Pilar Neira Huerta***
}

NEVES, S.C. \& NEIRA HUERTA, E. del P. Envolvimento pessoal e Interação efetiva em Enfermagem. Rev. Esc, Enf. USP, São Paulo, 22(2):231-235, ago. 1988.

A experiência vivenciada junto a uma criança com distúrbio sensorial motivou a elaboraçdo do presente trabalho. $O$ compromisso com o processo de aprendizagem de Enfermagem Pediátrica, no que diz respeito ao impacto da doença e da hospitalizaçdo na criança e em sua familia fez com que o valor e a habilidade da estudante de enfermagem, no atendimento das necessidades sentidas e demonstradas pela criança e sua familia, bem como a importancia do envolvimento pessoal e profissional - essenciais d̀ assistência efetiva em Enfermagem - fossem percebidos e APRENDIDOS pela estudante.

UNITERMOS: Relaçđes enfermeiro-paciente. Assistência de enfermagem. Enfermagem pediátrica.

\section{INTRODUÇÃO}

A motivação inicial deste trabalho foi o fato do curso de Enfermagem Pediátrica da Escola de Enfermagem ser diferente dos outros cursos na mesma escola ${ }^{(3)}$. O não ter respostas prontas, foi muito importante para que eu descobrisse minhas dificuldades e limitaçðes e para que eu refletisse, estudasse, vencesse a dificuldade inicial e aproveitasse ao máximo a oportunidade que a disciplina oferecia. Pude sentir o meu valor como aluna e adquirir aprendizagem de grande significado.

Senti-me envolvida e comprometida com a responsabilidade pelo processo de aprendizagem de Enfermagem Pediátrica, principalmente no referente ao impacto da doença e hospitalização na criança e sua família. O trabalho, desenvolvido junto à docente e às colegas do grupo de estágio, proporcionou-me crescimento e desenvolvimento significativos e gratificantes.

Através desta experiência, vivenciada em campo de estágio, espero frisar a importância do envolvimento pessoal e profissional na interação enfermeira-paciente-família, como fatores essenciais à Assistência Efetiva de Enfermagem.

A primeira visão que tive da criança, que contribuiu para a execução deste trabalho, foi um tanto chocante: ao chegar à enfermaria, logo observei a presença de uma criança "nova"; esta apresentava ptose da pálpebra esquerda e tinha um tam-

- Relato de experiência vivenciada no 5\% semestre, em 1985, na disciplina Enfermagem Pediátrica I e apresentado no XXXVIII Congresso Brasileiro de Enfermagem, Rio de Janeiro, outubro de 1986.

** Graduada em Enfermagem pela Escola de Enfermagem da USP, em 1986, e aluna do 5. semestre do Curso de Graduação da Faculdade de Direito da USP.

*** Enfermeira, Mestre em Enfermagem Pediátrica. Docente facilitadora da experiência relatada no trabalho e da aprendizagem decorrente da mesma. 
pão em sua narina esquerda, já todo vazado de secreção sangüinolenta, o que me causou má impressão. Olhei ao seu redor e ao seu lado percebi a presença de sua mãe, tomada pelo desânimo, cansada, preocupada. O contato inicial com a mãe foi feito pela docente; por ela ficamos sabendo da rápida evolução da doença, tendo transcorrido 15 dias desde que a criança deixara de enxergar. $O$ fato da criança ser filho de màe que havia tido 6 abortos e perdido um menino de 2 meses de vida, portador de Tetralogia de Fallot, acentuava seu medo e sua preocupaçãó. A mãe era auxiliar de enfermagem e cuidava de seu filho hospitalizado com muita dedicação, destreza e carinho, excluindo apenas os procedimentos dolorosos; manifestava, desse modo, sua necessidade não só de continuar a ser mãe da criança no hospital, como também, de utilizando-se de sua experiência e conhecimentos técnicos, prestar-lhe Assistência de Enfermagem. Senti necessidade de me aproximar daquela criança e de tentar ajudá-la, acalmá-la e também de, com a docente, assumir a assistência à familia.

Aproximei-me do berço da criança, quando esta estava sendo submetida a uma punçăo venosa; ela chorava muito e dizia coisas comoventes... Relirei-me emocionada. Observei a influência que a deficiência visual causava na criança, seu desespero em não poder prever o que lhe aconteceria; vontade de the prestar assistência de enfermagem adequada levou-me a procurar maiores informaçoes sobre seu caso clínico.

Até aquele dia, não havia sentido dificuldade alguma em relacionar-me com as crianças hospitalizadas, mas a partir daquele momento aquela criança "nova" passou a representar um desafio que eu estava disposta a enfrentar e vencer.

Consultando o prontuário, pude tomar conhecimento da evolução clinica de sua doença: "Criança de $3 a$ e $6 \mathrm{~m}$, com quadro de coriza, cefaléia c febre há 17 dias. Diagnosticado quadro de amigdalite, sem pús, e "catarreira"; sendo levada a serviço facultativo, foi-lhe receitado Amoxil que a criança recebeu por 3 dias; como apresentasse vômitos, este foi suspenso, sendo prescrito Bactrim. Há 13 dias, apresentou quadro de epistaxe, sendo encaminhada ao PS-Otorrino, onde foi feito tamponamento em narina esquerda. Após $2 \mathrm{~h}$ da retirada do tamponamento o sangramento recomeçou. Esses è isisódios repetiram-se e foram feitos tamponamentos e duas cauterizaçóes; há 3 dias apresenta fotofobia, lacrimejamento e ptose de pálpebra esquerda. A mãe percebeu mudança no comportamento da criança: prostração, apatia, agressividade, "enxergava bichos", intercalado de episódios em que a criança comportava-se normalmente. Nega alteração urinária. Ao exame físico: PA 140 x $100 \mathrm{~mm} \mathrm{Hg}$ (hipertensão a esclarecer) em ambos os membros. Hiperemia de orofaringe, micropoliadenopatia cervical e inguinal. Ptose de pálpebra esquerda. Paralisia do VI par intracraniano de causa a esclarecer. Processo Expansivo?',

Constatou-se que a criança era portadora de Rabdomiosarcoma embrionário de Rinofaringe. O lumor assentava-se em órbita, produzindo ptose, perda dos movimentos extra-oculares e em seios paranasais, assemelhando-se a um quadro de sinusite com dor, secreção sangüinolenta unilateral e epistaxc. Devido à exiensão e ao grande potencial invasivo do tumor, a abordagem cirúrgica era inviável; recorreu-se a uma associação de quimioterapia e radioterapia no tratamento; o prognóstico da criança revelava-se pouco animador.

Tudo isso fez com que eu procurasse e consultasse recursos bibliográficos pertinentes ${ }^{11.2}$ " t1 e promovesse discussỏes no grupo de estágio, das quais todas participávamos ativamente, pois, todas nós havíamos nos envolvido com o paciente, sua patologia e sua família. Sofriamos uma grande tensão emocional, que era visivel. 
Era difícil vivenciar situaçð̄es sobre as quais, até então, somente havíamos lido e/ou ouvido falar.

Observando o comportamento da criança, percebi sua agressividade, justificada pela compressão dos nervos, causada pelo tumor, e pelo fato dela ter perdido em tão pouco tempo a visão. Percebi, também, que a família comportava-se de acordo com o estado de humor da criança. O grupo apoiava a familia nessas oscilaçðes e éramos acolhidas e solicitadas, nessas e nas mais variadas situaçðes.

Observando a reação da criança às solicitaçðes da recreacionista, que se comunicava com ela através de um "gato imaginário", senti-me encorajada a abordar a criança. Assim, utilizando-me, a meu modo, do "gato imaginário", aproximei-me da poltrona onde a criança estava sentada, e comecei a conversar com ela; indagava a respeito de situaçðes pelas quais passara, de brincadeiras, jogos e cançðes; a reciprocidade foi tamanha, que mergulhei fundo no seu pequeno mundo; assim iniciamos um relacionamento de confiança mútua: Em pouco tempo a enfermaria adquiriu um ar mais leve e podiamos ver sorrisos estampados nos rostos de todos nós, criança, a família, as alunas, os funcionários, todos nós unidos num único sorriso; naquela manhă, a criança, o "meu gatinho Edgar", aceitou todas as refeiçðes e medicaçðes e deixou-se examinar, o que antes nunca havia sido conseguido em tal grau de cooperação por parte do meu pacientezinho.

Pude perceber a importância de oferecer esse apoio ao Edgar, apoio que lhe inspirava confiança e, através do qual eu podia sentir que conseguia amenizar sua angústia. Foi o primeiro passo rumo à Assistência Efetiva de Enfermagem.

Tentava suprir a deficiência visual de Edgar, utilizando variados recursos destinados a estimular seus outros sentidos, principalmente o tato e a audiçąo; isto era quase natural para mim, pois o fato de ter uma sobrinha de 4 anos, Joyce, faz com que eu esteja sempre atualizada nas novas músicas e brincadeiras infantis. Assim, cantava essas músicas para o Edgar; ele as adorava e cantarolava as que sabia e aprendia as que não conhecia. Eram momentos muito especiais, pois, além de ser muito gratificante vê-lo sorrir, nos uniam.

A família confiava plenamente nos cuidados que eu prestava ao Edgarzinho, deixando-o, inclusive, muitas vezes sozinho comigo. $\mathrm{O}$ apoio constante da docente, do grupo de estágio, da equipe, faziam com que eu caminhasse para uma Assistência Efetiva de Enfermagem.

Procurei no material lúdico disponivel na disciplina, um gato para tornar a nossa "brincadeira" mais efetiva e, desse modo, proporcionar ao Edgar também estímulo através do tato. Encontrei um gato de tecido bem macio, bem gordinho, porém... um pouco judiado. Não tive dúvidas: levei-o para casa, costurei-o onde era preciso, fiz uma reforma geral, pois, mesmo sabendo que o Edgar năo o enxergaria, para mim fazia-se necessário o gato apresentar-se bem. Na manhã seguinte cheguei à unidade, com o gato. Estava ansiosa, esperando a chegada da docente, pois não sabia como iria estabelecer um limite de tempo para a permanência do brinquedo junto à criança; felizmente, o brinquedo me foi liberado para que eu o oferecesse como um presente ao Edgar.

Aproximei-me do berço. O pai do Edgar anunciou-lhe minha presença e fui muito bem acolhida; disse-lhe que havia trazido um presente, o gato, e coloquei-o a seu alcance; ele o segurou, foi pouco a pouco examinando-o, palpando-o nos mínimos detalhes; a superficie de contato era excelente, pois propiciava um ótimo desenvolvimento de toque do Edgar; o gato foi sendo "desvendado" pela criança e logo foi vítima de um puxão em seu longo rabo, o que eu já previra "Olha mãe, que boni- 
tinho, é fofinho, que gracinha, que bonito" - e o Edgar abraçava bem forte, acariciando-o ternamente. Foi uma cena maravilhosa!

A essa altura, a criança apresentava uma boa melhora e transparecia na familia, tal melhora. O Edgar agora conversava com a maioria das pessoas, alimentava-se, brincava e até andava auxiliado por seus pais ou por mim, que era o "seu gatinho". Era gratificante observar e sentir a confiança que a família depositava em mim; na assistência que eu prestava a seu filho, percebiam que eu conseguia estimulá-lo, animá-lo.

Procurava fazer com que o Edgar percebesse de alguma maneira os objetos, as pessoas, todo o ambiente à sua volta. Foi muito bonito o dia em que perguntei se ele gostaria de tocar o bebê que ocupava o berço ao seu lado e que chorava durante a noite, perturbando o seu sono; Edgar mostrou-se interessado e demonstrou muito cuidado e carinho ao tocar o bebê. A necessidade que o Edgar sentia de integrar-se a um mundo, que já não era mais o seu, era enorme e ele a expressava através de seus comportamentos e expressðes não verbais.

Como o tumor havia regredido consideravelmente, o estado geral da criança era bom e, particularmente pelo temor de que a criança contraísse alguma infecção no hospital, a equipe médica informou à familia a decisão de dar alta hospitalar à criança, decisão que a familia, surpresa, achou ótima.

Nesse momento houve avaliação da assistência que eu prestara, avaliação esta da maior importância pois foi feita pelos receptores da mesma: agradecimentos, reconhecimentos, emoçðes,... o Edgar iria para sua casa.

Na manhà seguinte, ao chegar à enfermaria, o fato de encontrar o Edgar "ainda" em seu bercinho, fez com que eu levasse o maior susto. Temi uma piora, o tumor,... mas felizmente năo era nada disso! O funcionário encarregado da radioterapia havia faltado e, por esse motivo, a ida de Edgar para casa tinha sido adiada para o dia seguinte.

A enfermaria ficou vazia sem ele, sem o seu sorriso. Senti muito, mas foi o meIhor que poderia ter acontecido a ele e à familia, pois, além do estado de doença da criança, o estresse causado pela hospitalizaçăo acrescentava na familia uma carga muito pesada de desgaste emocional; o "estar em casa" Ihes traria aquela segurança, naquele momento tão necessária para que pudessem enfrentar melhor a situação.

Desejei à criança e a seus pais os melhores votos de paz, amor, saúde e esperança. "Vá meu pequeno, seu lar o espera, que Deus os ajude a continuar com essa força espiritual e moral, e que Deus continue a me dar essa força para que eu possa continuar a ajudar o meu próximo".

Através dessa experiência pude sentir o meu valor como aluna de Enfermagem no atendimento das necessidades sentidas e demonstradas pela criança e sua familia, verificando que o envolvimento pessoal e profissional foram elementos primordiais nessa interação Enfermeira-Paciente e Família, nessa Assistência Efetiva de Enfermagem.

Ao avaliar a experiência, pude constatar tambèm que fọi muito gratificante e emocionante estabelecer relacionamento de ajuda com uma criança que apresentava distúrbio sensorial. $\mathrm{O}$ carinho, o afeto, a atenção dispensados ao Edgar foram, para mim, fatores de crescimento, desenvolvimento e amadurecimento pessoal e profissional. A partir da motivação inicial, da vontade verdadeira de prestar Assistência e de um tipo de Interaçăo, que realmente permitiu compreender as necessidades da criança e seus pais, senti-me $C A P A Z$ de prestar Assistência Efetiva de Enfermagem.

Obrigada querida criança! 
NEVES, S.C. \& NEIRA HUERTA, E. del P. Personal involvement as an essential factor in nurse-patient interaction. Rev. Esc. Enf. USP, Såo Paulo, 22(2):231-235, Aug. 1988.

The nurse-patient relationship of the author and a child with a sensory disorder motivated this student nurse to elaborate the present work. As part of her own direct participation in the learning process during her pediatric nursing course, the student describes what she learned while studying the impact of illness and hospitalization on a child and his family. Through this experience she came to recognize not only her own value and hability to meet the needs of the child and his family, but also the importance of personal and professional involvement in order to provide effective nursing care.

UNITERMS: Nurse-patient relations. Nursing care. Pediatric nursing.

\section{REFERÊNCIAS BIBLIOGRÁFICAS}

1. BIANCHI, A. et alii.Tumores. In: MARCONDES, E. Pediatria błsica. 7 ed., Săo Paulo, Sarvier, 1985. Seçào III, p. 305-39.

2. MENDONÇA, N. Mauual do diagnóstico do cincer na criança. Sociedade Brasileira de Cancerologia, 1984. $100 \mathrm{p}$.

3. NEIRA HUERTA, E. del P. et alii. O curso de Enfermagem Pediátrica I na Escola de Enfermagem da USP. Rev. Esc. Enf. USP, Săo Paulo, 19(3):247-62, 1985.

4. WHALEY, L.F. \& WONG, D.L. Essentials of pediatric nursing. 2. ed., Saint Louis, Mosby, 1985. caps. $16,17,18$ e 19.

Recebido para publicaçao em 12-01-87.

Aprovado para publicação em 6-88. 